\title{
A case report and review of the literature of Bouveret syndrome
}

\author{
G Singh, N Merali, S Shirol, P Drymousis, S Singh, D Veeramootoo \\ Upper Gastrointestinal Surgery, Frimley Park Hospital, Frimley Health NHS Trust, Frimley, \\ Camberley, UK
}

\section{ABSTRACT}

Bouveret syndrome is a rare variant of gallstone ileus causing gastric outlet obstruction. It results from the formation of either a cholecystoduodenal or a cholecystogastric fistula and subsequent migration of gallstone into the duodenum or pylorus of stomach, causing obstruction. The first case was reported by Leon Bouveret in 1896. We report a case illustrating the rarity and severity of this condition, together with a review of the literature of the different methods of endoscopic and surgical treatment.

\section{KEYWORDS}

Bouveret syndrome - Gallstone disease - General surgery - Education - Gastric outlet obstruction

Accepted 14 October 2019

CORRESPONDENCE TO

N Merali, E: nabeel.merali@gmail.com

\section{Background}

Bouveret syndrome is a rare cause of gastric outlet obstruction, representing less than $3 \%$ of cases of gallstone ileus. ${ }^{1}$ It is an acquired cholecystoenteric fistula between the gallbladder and the duodenum. The formation of the fistula is caused by chronic inflammation, with an increase in the intraluminal pressure, directly causing wall ischaemia and perforation allowing gallstone passage into the bowel. ${ }^{2}$ We report a case of Bouveret syndrome, illustrating the rarity and severity of this condition with a review of the literature on the different methods of endoscopic and surgical treatment.

\section{Case history}

An 89-year-old man with a past medical history of atrial fibrillation, hypertension and gastro-oesophageal reflux disease presented to the emergency department with acute confusion, coffee-grounds vomiting and anorexia. On examination, he had a distended, tender abdomen with localised guarding in the epigastrium. He had a white blood cell count of $13 \times 10^{9} /$ l (normal range $4-10 \times 10^{9} /$ ) and C-reactive protein of $43 \mathrm{mg} / \mathrm{dl}$ (normal range 0.8-3.0 $\mathrm{mg} / \mathrm{dl})$. An initial diagnosis of upper gastrointestinal bleeding led to the patient having an oesophagogastroduodenoscopy, which demonstrated an erythematous oesophagus and a swollen pylorus with a large obstructing stone (Fig 1). After a second endoscopic attempt to remove the stone failed, the patient was referred to the emergency surgical team. Computed tomography demonstrated a 3.5 cm gallstone lying in the second part of duodenum, which extended proximally through the pylorus leading to gastric outlet obstruction (Fig 2).

At surgery, an upper-midline mini-laparotomy and longitudinal pyloromyotomy was made to extract multiple large gallstones (Fig 3) aided by Desjardins forceps. The pylorus was closed transversely primarily with 3.0 polydioxanone interrupted extramucosal sutures followed by an omental patch. An abdominal drain was placed intraoperatively, with an uneventful postoperative period.

The patient was treated with total parenteral nutrition support, proton pump inhibitor and prophylactic intravenous broad-spectrum antibiotics. He was managed in intensive care for the first 24 hours. On day five, oral nutrition was commenced after a normal Gastrografin swallow study. He was discharged on the seventh day from his admission date and was reviewed in the outpatient clinic with no further concerns.

\section{Discussion}

Bouveret syndrome is a rare variant of gallstone ileus causing gastric outlet obstruction. The common risk factors are being elderly with an average age of 70 years, female sex and gallstones greater than $2.5 \mathrm{~cm}$, which have higher chances of impaction and subsequent bowel obstruction. ${ }^{4,5}$ The symptoms are nausea and vomiting (85\%), abdominal pain $(70 \%)$, haematemesis, weight loss and anorexia. Clinical signs are obstructive in nature, such as abdominal tenderness and distension with altered bowel habits. Findings suggestive of Bouveret syndrome include Rigler's 
triad: a dilated stomach, pneumobilia and a radio-opaque shadow suggesting an enteric gallstone. ${ }^{6}$ The mainstay of management is surgical intervention to remove the
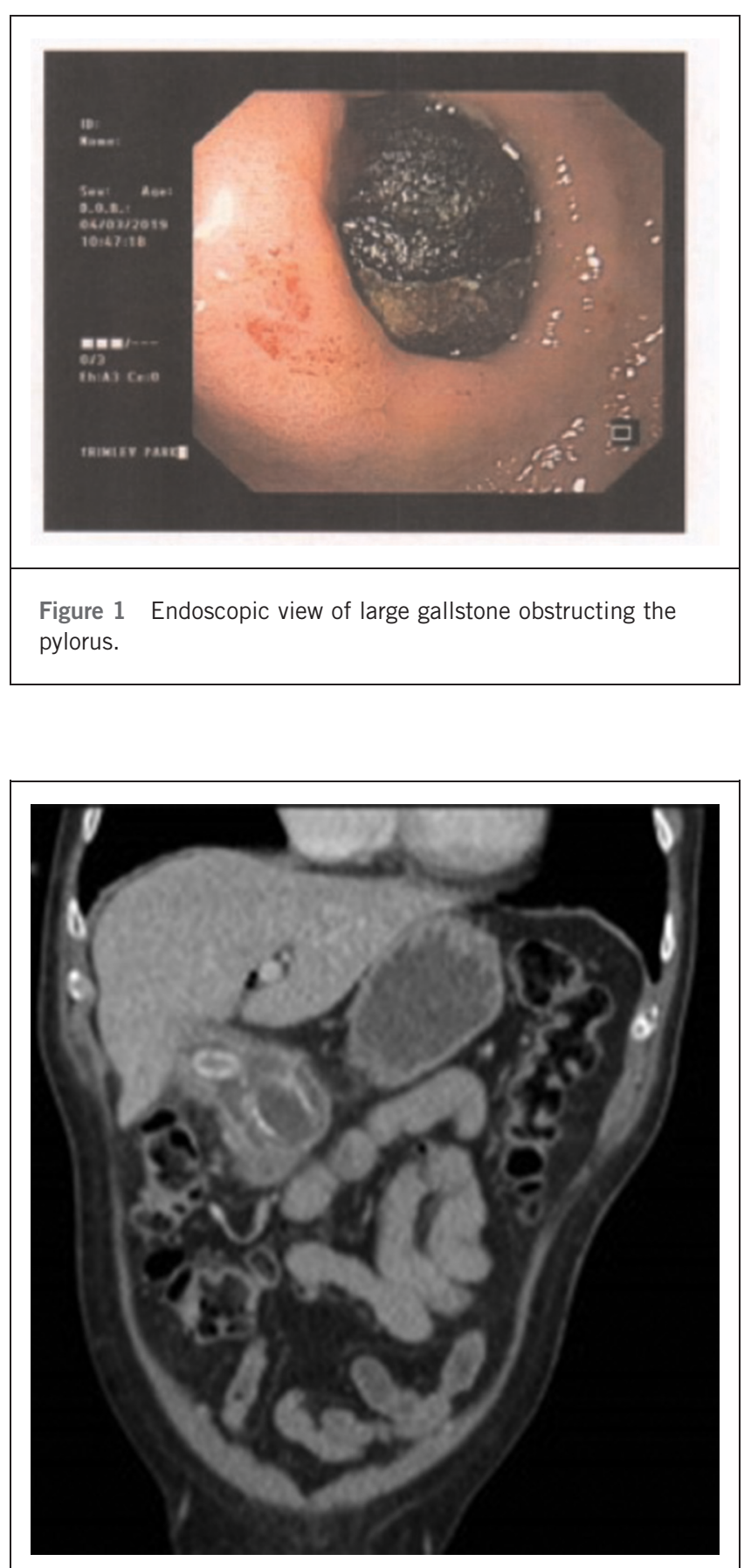

Figure 2 There is a large calcified gallstone lying within the pylorus of the stomach, measuring $3.5 \mathrm{~cm}$. The proximal stomach is fluid filled but not significantly dilated. There is a further calculus lying lateral to the pylorus which lies within the cholecystoenteric fistula. There is associated pneumobilia and gas within the gallbladder.

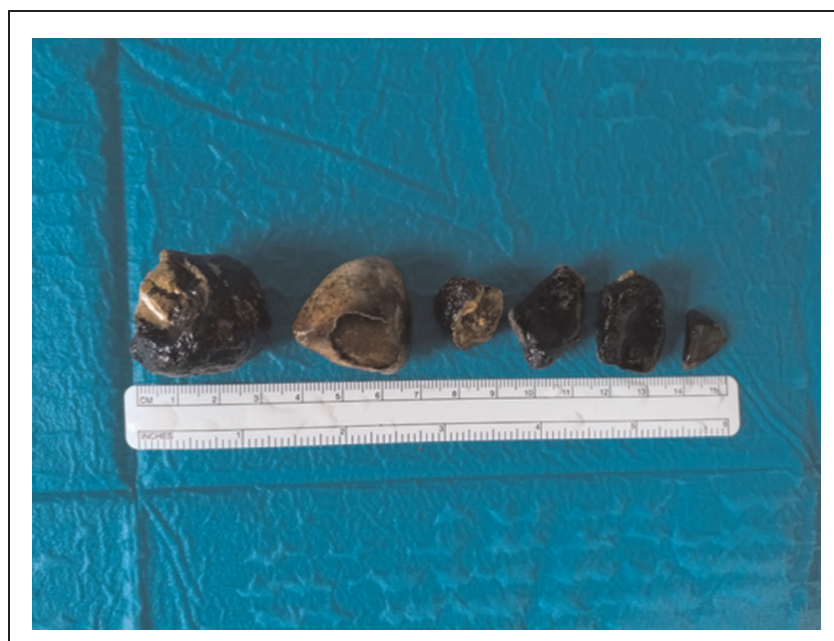

Figure 3 Extraction of multiple large gallstones.

obstructing gallstone. Non-operative management is associated with a mortality of $26.5 \% .^{7}$

\section{Non-operative management (endoscopic options)}

Bedogni et al described the first successful case of endoscopic treatment of Bouveret syndrome in $1985 .^{8}$ Endoscopic visualisation of the stone is possible in only about $69 \%$ of cases, owing to submucosal embedding of the stone. ${ }^{9}$ The endoscopic findings suggestive of Bouveret syndrome are dilated stomach containing old digested food from gastrointestinal obstruction, together with a hard, non-fleshy and convex mass at the obstruction. ${ }^{5}$ Multiple endoscopic modalities have been used for treatment of Bouveret syndrome including endoscopic stone removal with nets or baskets. ${ }^{6}$ For stones that cannot be removed using nets or baskets, lithotripsy techniques such as mechanical, electrohydraulic, intracorporeal lase, and extracorporeal shockwave therapy can be used to break the stone prior to endoscopic extraction. After lithotripsy, all fragments of the stone must be removed to prevent a postoperative gallstone ileus. ${ }^{2}$ Risks include intestinal wall haemorrhage or perforation. ${ }^{10}$ Note that $42 \%$ of surgical patients have already failed an endoscopic trial for gallstone removal. ${ }^{11,12}$

\section{Operative management}

Surgery is required in about $90 \%$ of cases, with mortality ranging from $19 \%$ to $24 \% .^{3}$ Within the current literature, there are three surgical approaches. A common surgical approach consists of laparoscopic or open gastrotomy, pyloromyotomy or duodenotomy at or immediately proximal to the site of obstruction. ${ }^{13,14}$ If it is possible to manoeuvre an impacted duodenal gallstone into the stomach a gastrotomy can be applied for stone removal. ${ }^{15}$ When the gallstone is present in an area that may be difficult to access during open surgery, endoscopy can be used as an adjunct to help mobilise the stone into a more favourable location for performing enterotomy. ${ }^{6}$ 
Table 1 An overview of existing evidence and their respective management strategies and outcomes.

\begin{tabular}{|c|c|c|}
\hline Study & Type & Management strategies and outcomes \\
\hline \multirow[t]{3}{*}{ Caldwell et al (2018) } & \multirow[t]{3}{*}{ Case report and literature review } & Site: $6 \times 4 \mathrm{~cm}$ gallstone in gastric antrum. \\
\hline & & $\begin{array}{l}\text { Procedure: laparoscopy; open cholecystectomy + partial gastrectomy } \\
+ \text { Billroth II gastrojejunostomy + intraoperative cholangiogram. }\end{array}$ \\
\hline & & $\begin{array}{l}\text { Outcome: 1) first-line option, endoscopic retrieval } \pm \text { use of adjuncts; } \\
\text { 2) laparoscopic extraction of gallstone through an enterotomy; } \\
\text { 3) stone extraction + cholecystectomy + fistula repair. }\end{array}$ \\
\hline \multirow[t]{2}{*}{ Bhattarai et al (2016) ${ }^{14}$} & \multirow[t]{2}{*}{ Case report } & Site: first part of the duodenum; \\
\hline & & Procedure: laparotomy + anterior pyloromyotomy + stone extraction. \\
\hline \multirow[t]{2}{*}{ Mir S, et al $(2015)^{16}$} & \multirow[t]{2}{*}{$\begin{array}{l}\text { Systematic review of } 113 \text { cases } \\
\text { of recurrent gallstone ileus } \\
\text { reported in } 91 \text { articles }\end{array}$} & $\begin{array}{l}\text { Management: } 1 \text { ) enterolithotomy ( } 86.7 \%) \text {; } \\
\text { 2) enterotomy with cholecystectomy and repair of fistula. }\end{array}$ \\
\hline & & $\begin{array}{l}\text { Outcome: mortality in the past } 25 \text { years associated with: } \\
\text { enterolithotomy }(4.8 \%) \text {, single stage surgery }(22 \%) \text {. }\end{array}$ \\
\hline \multirow[t]{3}{*}{ Qasaimeh et al $(2014)^{1}$} & \multirow[t]{3}{*}{ Case report and literature review } & Site: $3.5 \times 5 \mathrm{~cm}$ gallstone in the first part of the duodenum. \\
\hline & & $\begin{array}{l}\text { Procedure: laparotomy + anterior longitudinal duodenotomy } \\
+ \text { stone extraction. }\end{array}$ \\
\hline & & $\begin{array}{l}\text { Outcome: } 1 \text { ) simple stone extraction related mortality rate } 12 \% \text {; } \\
\text { 2) definitive one-stage procedure-related mortality rate } 20-30 \% \text {. }\end{array}$ \\
\hline \multirow[t]{3}{*}{ Keller et al $(2014)^{13}$} & \multirow[t]{3}{*}{ Case report and literature review } & Site: duodenal bulb. \\
\hline & & Procedure: laparotomy + gastrotomy + stone extraction. \\
\hline & & Management: 1) endoscopic retrieval; 2) enterolithotomy. \\
\hline \multirow[t]{4}{*}{ Mavroeidis et al (2013) ${ }^{12}$} & \multirow[t]{4}{*}{ Case report and literature review } & Site: $5.7 \times 3.8 \times 4 \mathrm{~cm}$ gallstone in $\mathrm{D} 2+\mathrm{D} 3$. \\
\hline & & $\begin{array}{l}\text { Procedure: laparotomy + Kocher's manoeuvre + jejunotomy } \\
+ \text { stone extraction. }\end{array}$ \\
\hline & & $\begin{array}{l}\text { Management: 1) endoscopy-assisted retrieval; } \\
\text { 2) simple enterolithotomy; 3) one-stage procedure. }\end{array}$ \\
\hline & & $\begin{array}{l}\text { Outcome: simple duodenotomy related mortality } 12 \% \text {; } \\
\text { combined treatment-related mortality } 20-30 \% \text {. }\end{array}$ \\
\hline \multirow[t]{4}{*}{ Doycheva et al (2009) ${ }^{11}$} & \multirow[t]{4}{*}{ Case report and literature review } & Site: $3.3 \mathrm{~cm}$ gallstone in the second part of the duodenum. \\
\hline & & $\begin{array}{l}\text { Procedure: endoscopic retrieval using various devices } \\
\text { including a retrieval net, snare, stone extracting basket, } \\
\text { mechanical lithotripter and lithotripsy basket. }\end{array}$ \\
\hline & & $\begin{array}{l}\text { Management: 1) initial treatment option endoscopic retrieval; } \\
\text { 2) simple enterolithotomy; 3) combined procedure. }\end{array}$ \\
\hline & & $\begin{array}{l}\text { Outcome: } 1 \text { ) simple duodenotomy related mortality } 12 \% \text {; } \\
\text { 2) combined treatment-related mortality } 20-30 \% \text {. }\end{array}$ \\
\hline \multirow[t]{2}{*}{ Park et al (2009) $)^{10}$} & \multirow[t]{2}{*}{ Case report } & $\begin{array}{l}\text { Site: cystic lesion of the first and second parts of the duodenal wall } \\
\text { (containing multiple gallstones) causing gastric outlet obstruction. }\end{array}$ \\
\hline & & $\begin{array}{l}\text { Procedure: laparotomy + cholecystectomy }+ \text { excision of a portion } \\
\text { of the duodenal wall. }\end{array}$ \\
\hline \multirow[t]{2}{*}{ Ayantunde et al (2007) $)^{2}$} & \multirow[t]{2}{*}{ Retrospective review of 22 cases } & $\begin{array}{l}\text { Management: 1) } 20 \text { patients had enterolithotomy; } \\
\text { 2) } 2 \text { patients had a one-stage procedure. }\end{array}$ \\
\hline & & $\begin{array}{l}\text { Outcome: } 5 \text { perioperative deaths, } 1 \text { episode of cholangitis } \\
18 \text { months after enterolithotomy alone. }\end{array}$ \\
\hline Cappell et al $(2006)^{5}$ & Literature review of 128 cases & $\begin{array}{l}\text { Outcome: endoscopy revealed gastroduodenal obstruction in nearly } \\
\text { all cases but identified the obstructing stone in only } 69 \% \text { cases. } \\
\text { The following endoscopic findings are suggestive of Bouveret } \\
\text { syndrome: a dilated stomach containing old digested food from } \\
\text { gastrointestinal obstruction together with a hard and non-fleshy } \\
\text { mass at the obstruction. }\end{array}$ \\
\hline
\end{tabular}




\begin{tabular}{|c|c|c|}
\hline Lowe et al (2005) ${ }^{3}$ & $\begin{array}{l}\text { Literature review of } 44 \text { cases } \\
\text { from } 39 \text { papers }\end{array}$ & $\begin{array}{l}\text { Management: } 1 \text { ) } 91 \% \text { of patients underwent surgery } \\
\text { ( } 64 \% \text { laparoscopy/open enterolithotomy, } 36 \% \text { one-stage repair); } \\
\text { 2) } 9 \% \text { of patients had nonsurgical treatment. } \\
\text { Outcome: overall mortality } 12-24 \% \text {. }\end{array}$ \\
\hline \multirow[t]{2}{*}{ Reisner et al $(1994)^{7}$} & Literature review of 1001 cases & $\begin{array}{l}\text { Management: 1) simple enterolithotomy + stone extraction; } \\
\text { 2) one-stage procedure. }\end{array}$ \\
\hline & & $\begin{array}{l}\text { Outcome: enterolithotomy-associated mortality } 11.7 \% \text {; } \\
\text { one-stage procedure-associated mortality } 16.9 \% \text {. }\end{array}$ \\
\hline
\end{tabular}

Many authors have commonly used the 'open gastrostomy' approach as described in our case. Laparoscopic enterolithotomy and gastrostomy have been reported and are safe and effective in the management of this condition. It is important to examine the remaining small intestine to look for any residual stones that may cause postoperative gallstone ileus. If there are no residual stones in the gallbladder with a patent cystic duct, theoretically the simple stone extraction method can lead to the fistula closing spontaneously. ${ }^{6,9}$

The second approach of surgery is more invasive and continues to be actively debated on whether patients should have a 'one-stage procedure' that involves a gastrotomy or enterotomy and stone extraction, with or without cholecystectomy and repair of cholecystoduodenal fistula. This may require partial resection of the duodenum and common bile duct surgery with tertiary centre involvement. Mir et al reports in the past 25 years, enterotomy alone as the treatment for recurrent gallstone ileus was associated with mortality of $4.8 \%$. Whereas surgery involving enterotomy with cholecystectomy and repair of cholecystoenteric fistula had a mortality rate of $22.2 \% .^{16}$ The third approach is a 'two-stage procedure' involves enterotomy with stone extraction followed by an elective cholecystectomy and repair of fistula, once the inflammatory process around the gallbladder improved. The benefits include preventing recurrent cholecystitis, cholangitis, gallstone ileus and the occurrence of fistulising gallbladder carcinoma. ${ }^{6,9}$ Chowbey et al illustrated the success of the laparoscopic endostapling for patients with a cholecystoenteric fistula; however, the mean age of the patients was 57.2 years with no comment on comorbidities. ${ }^{17}$ Reisner et al reviewed 1001 reported cases of gallstones ileus and concluded a one-stage procedure carried a mortality of $16.9 \%$, compared with $11.7 \%$ for simple enterolithotomy. ${ }^{7}$ Table 1 gives an overview of existing evidence and their respective management strategies and outcomes.

There is a general consensus between surgeons that less is better when treating patients with Bouveret syndrome. ${ }^{18}$ Historically, the one-stage approach was found to be associated with a high rate of postoperative morbidity and mortality; hence most surgeons advocate the enterolithotomy-only approach. ${ }^{19}$ However, our review highlights a lack of empirical evidence to support one type of surgery over another. Owing to the rarity of the condition, the data are scarce on primary repair compared with spontaneous closure of the fistula and the true benefits of performing cholecystectomy.

\section{Conclusion}

A high degree of suspicion is required for diagnosis of Bouveret syndrome and it may be diagnosed incidentally on initial imaging workup for gastric outlet obstruction. Although there is no standardised protocol for its treatment, endoscopy is a useful initial diagnostic and potential therapeutic adjunct. In the case of impacted stones, assistant options such as lithotripsy can be used for fragmentation of the stone and endoscopic retrieval. Owing to the high failure rate of endoscopy, surgery remains the mainstay treatment modality. Laparoscopic or open extraction of the stone through a gastrotomy or duodenotomy is the treatment of choice. Enterotomy alone is the preferred option in elderly patients with multiple comorbidities. Cholecystectomy and fistula repair as a single- or a two-stage procedure can be considered after careful planning.

\section{References}

1. Qasaimeh GR, Bakkar S, Jadallah K. Bouveret's syndrome: an overlooked diagnosis: a case report and review of literature. Int Surg 2014; 99: 819-823.

2. Ayantunde AA, Agrawal A. Gallstone ileus: diagnosis and management. World J Surg 2007; 31: 1,294-1,299.

3. Lowe AS, Stephenson S, Kay CL, May J. Duodenal obstruction by gallstones (Bouveret's syndrome): a review of the literature. Endoscopy 2005; 37: 82-87.

4. Abou-Saif A, Al-Kawas FH. Complications of gallstone disease: Mirizzi syndrome, cholecystocholedochal fistula, and gallstone ileus. Am J Gastroenterol 2002; 97: 249-254.

5. Cappell M, Davis M. Characterization of Bouveret's syndrome: a comprehensive review of 128 cases. Am J Gastroenterol 2006; 101: 2,139-2,146.

6. Caldwell K, Lee S, Leggett $P$ et al. Bouveret syndrome: current management strategies. Clin Exp Gastroenterol 2018; 11: 69-75.

7. Reisner RM, Cohen JR. Gallstone ileus: a review of 1001 reported cases. Am Surg 1994; 60: 441-446.

8. Bedogni G, Contini S, Meinero M et al. Pyloroduodenal obstruction due to a biliary stone (Bouveret's syndrome) managed by endoscopic extraction. Gastrointest Endosc 1985; 31: 36-38.

9. Watson RS, Folkers TE. Van Every MJ. A multidisciplinary approach to management of Bouveret syndrome. Clin Med Res 2018; 16: 73-75.

10. Park SH, Lee SW, Song TJ. Another new variant of Bouveret's syndrome. World J Gastroenterol 2009; 15: 378-379.

11. Doycheva I, Limaye A, Suman A et al. Bouveret's syndrome: case report and review of the literature. Gastroenterol Res Pract 2009; 2009: 914951.

12. Mavroeidis VK, Matthioudakis DI, Economou NK, Karanikas ID. Bouveret syndrome: the rarest variant of gallstone ileus. A case report and literature review. Case Rep Surg 2013; 2013: 839370. 
13. Keller M, Epp C, Meyenberger C, Sulz MC. Unspecific abdominal symptoms and pneumobilia: a rare case of gastrointestinal obstruction. Case Rep Gastroenterol 2014; 8: 216-220.

14. Bhattarai M, Bansal P, Patel B, Lalos A. Exploring the diagnosis and management of Bouveret's syndrome. JNMA J Nepal Med Assoc 2016; 54(201): 33-35.

15. Gallego Otaegui L, Sainz Lete A et al. A rare presentation of gallstones: Bouveret's syndrome, a case report. Rev Esp Enferm Dig 2016; 108 : 434-436.
16. Mir S, Hussain Z, Davey A et al. Management and outcome of recurrent gallstone ileus: a systematic review. World J Gastroenterol 2015; 7: 152-159.

17. Chowbey PK, Bandyopadhyay SK, Sharma A et al. Laparoscopic management of cholecystoenteric fistulas. J Laparoendosc Adv Surg Tech A 2006; 16 $467-472$.

18. Rabie MA, Sokker A. Cholecystolithotomy, a new approach to reduce recurrent gallstone ileus. Acute Med Surg 2019; 6: 95-100.

19. Scuderi V, Adamo V, Naddeo M et al. Gallstone ileus: monocentric experience looking for the adequate approach. Updates Surg 2017; 70: 503-511. 